\title{
Ensino superior e desenvolvimento de habilidades para a empregabilidade: explorando a visão dos estudantes ${ }^{1}$
}

Introdução

A alegada lacuna entre o que as universidades proporcionam para o desenvolvimento de habilidades para a empregabilidade e o que os empregadores precisam foi um argumento decisivo para a inclusão de conteúdos voltados para o desenvolvimento dessas habilidades no currículo do ensino superior. No entanto a introdução de estratégias mais abrangentes e de iniciativas para favorecer o desenvolvimento de habilidades para a empregabilidade, que favorecessem a empregabilidade dos estudantes não ocorreu sem conflitos. 0 s acadêmicos argumentam que os empregadores não são realistas ao apresentarem suas exigências no que diz respeito às habilidades que desejam que os candidatos aos empregos tenham (Bennett et al. 2000). O sempregadores, por outro lado, afirmam que há uma lacuna entre a concepção que os responsáveis pelo ensino superior têm sobre aquilo que os empregadores querem e o que eles realmente precisam; ao mesmo tempo, criticam a falta de participação dos estudantes na definição da agenda de habilidades a serem desenvolvidas (M iller Smith 2002). Alguns autores têm abordado a falta de atenção à visão dos estudantes. Bennett

* London School of Economics and Political Science, Department of Social Policy, Houghton Street, London W C2A 2AE. M iddlesex University, School of Health and Social Sciences, Q ueensway, Enfield, M iddlesex EN 3 4SA. Inglaterra.

1 Tradução do original em inglês de M arcelo 0 tto Severo e revisão técnica de Soraya Vargas Cortes. 
Sociologias, Porto Alegre, ano 8, no 16, jul/dez 2006, p. 126-155

et al. (2000), por exemplo, apontam para a ausência de pesquisa empírica sobre: a opinião do estudante quanto à provisão de habilidades genéricas; as experiências dos estudantes; os resultados observados de diferentes formas de provisão de habilidades e a transferência do lugar para a aquisição da habilidade para os locais de trabalho. Muitos anos se passaram, e as opiniões e experiências dos estudantes continuam, em grande parte, ausentes da pesquisa e do debate (Shah et al. 2004; Burke et al. 2005). Como a participação dos estudantes é importante para o aprimoramento do currículo, este artigo examina a posição dos mesmos em relação ao desenvolvimento de habilidades para o trabalho no processo de ensino e está baseado em um questionário estruturado que foi aplicado a 60 alunos de graduação que cursam bacharelado em políticas sociais e bacharelado combinado em políticas sociais e Sociologia, em uma universidade londrina criada depois de 1992. 0 artigo examina a percepção dos estudantes sobre a provisão de habilidades e suas preferências quanto ao desenvolvimento e avaliação das habilidades para a empregabilidade. U ma limitação evidente deste estudo é o tamanho reduzido da amostra, que não é representativa de percepções de uma população estudantil altamante diversificada. Entretanto a pesquisa não se propõe a medir ou avaliar atitudes formalmente, mas antes, identificálas e explorá-las para estabelecer um amplo quadro de opiniões sobre o tema. Os resultados serviriam para desenvolver estratégias de ensino e aprendizagem, com o objetivo de proporcionar embasamento acadêmico para a área do desenvolvimento de habilidades para a empregabilidade, que fossem aceitáveis tanto para os que aprendem quanto para os que ensinam.

0 artigo inicia com uma breve descrição do contexto em transformação no qual se inserem a questão e as práticas de desenvolvimento de habilidades para a empregabilidade no ensino superior do Reino U nido, e as definições usadas para tratar da empregabilidade. A seguir é apresentada 
Sociologias, Porto Alegre, ano 8, no 16, jul/dez 2006, p. 126-155

uma análise da literatura relevante para o estudo e do contexto teórico que o cerca. Nestas seções são ressaltadas algumas das controvérsias existentes sobre o tema do desenvolvimento de habilidades para a empregabilidade. 0 artigo analisa, então, as percepções dos estudantes sobre três aspectos: provisão, potencialização e avaliação das habilidades para o trabalho, tendo em vista a empregabilidade. Examina quais aspectos do desenvolvimento dessas habilidades os estudantes consideram aceitáveis para serem incluídos no currículo e valorizados para o planejamento da carreira. A seção final sintetiza os pontos examinados no artigo e discute as implicações que eles trazem para a teoria e para a prática.

\section{Contexto em transformação e o desenvolvimento de habili- dades para a empregabilidade no ensino superior}

U ma série de mudanças nos contextos político e econômico estimulou o debate sobre o desenvolvimento das habilidades para a empregabilidade no ensino superior, no Reino U nido. Em 1987, o governo britânico publicou uma análise e em conjunto de propostas (white paper) intitulada 'Higher Education: Meeting the Challenge'. 0 texto apontava que os baixosíndices de participação tanto na educação continuada quanto na superior influenciavam negativamente a competitividade britânica em relação a outras economias desenvolvidas. Enfatizava também a necessidade de formar graduados com habilidadesacadêmicas e profissionais que incluíssem competências, posturas e valores, capazes de ajudar a revitalizar a economia. Apósa publicação desse documento houve aumento no número de estudantes e na interferência do governo no currículo do ensino superior (Bennett et al. 2000).

2 Nota do tradutor: White Paperé o documento através do qual o governo britânico apresenta uma proposta de nova legislação e convida as partes envolvidas a se manifestarem. Neste caso, trata do ensino superior no Reino Unido. 
O aumento no número de estudantes durante a década de 1990 mudou a composição do corpo estudantil. U ma parcela significativa das novas admissões era composta por adultos e estudantes de tempo parcial (part-time students), ${ }^{3}$ provenientes de grupos socioeconômicos menos favorecidos, e mulheres. Esse aumento, assim como a mudança na composição do corpo discente, deu-se no momento em que se reduziam o financiamento por estudante e o investimento na área do ensino superior e se tornava freqüente a demanda por uma maior eficiência nos serviços públicos. As mudanças resultantes - que incluíam: a modularização dos programas; o aumento no número de horas de estudo independente para os estudantes; turmas maiores e, conseqüentemente, um número maior de alunos por professor (pelo menos inicialmente), bem como uma maior quantidade de contratos temporários - tiveram como conseqüência uma crescente preocupação com a qualidade do ensino (Bennett et al. 2000). Enquanto a atenção do governo direcionava-se para processos de auditoria e de controle de qualidade, para informar as decisões sobre financiamento, as universidades estavam preocupadas em atender às exigências que 0 ingresso dos novos alunos trazia, em termos de provisão de habilidades. Muitos deles precisavam desenvolver tanto as habilidades de estudo quanto habilidades básicas.

O crescimento no número de graduados provocou um aumento da competição no mercado de trabalho. Muitos dos novos graduados ingressaram em empregos nos quais não utilizavam os conhecimentos específicos adquiridos nos cursos de graduação nem obtiveram empregos de nível superior. Estes fatos levaram à evidente conclusão de que o treinamento universitário teria que combinar o ensino de matérias específicas com o ensino de habilidades que pudessem ser transferidas a diversas áreas de trabalho

3 Estudantes que não assumem uma carga horária completa, em termos de estudose curso, estudantes especiais ou de cursos por correspondência. 
Sociologias, Porto Alegre, ano 8, no 16, jul/dez 2006, p. 126-155

(Fallows e Steven 2000). Teve grande impacto nas políticas governamentais o reconhecimento das novas necessidades que as mudanças econômicas provocavam. Cada vez mais exigia-se uma força de trabalho flexível, com múltiplas habilidades, capaz de mudar e de se adaptar a novos empregose ambientes de trabalho, que facilitasse o trabalho em equipe, e não, trabaIhadores com conhecimentos e habilidades especializados em áreas restritas. (Little 2001). Pesquisas com empregadores demonstraram seu descontentamento com as habilidades de muitos dos novos graduados, e sua preferência por graduados com habilidades básicas ou transferíveis. U ma pesquisa de 1995, para a Association of Graduate Recruiters, demonstrou que muitos empregadores preferiam alunos autoconfiantes e graduados, capazes de assumir a responsabilidade pelo seu próprio desenvolvimento profissional (Fallows e Steven 2000; Dunne 1999a).

Foi neste cenário de mudanças políticas e econômicas, que as metas e os resultados da educação superior foram redefinidos. As duas grandes metas do ensino superior - o ensino das habilidades que contribuem para a sociedade e para o desenvolvimento da mente do indivíduo -, conforme observado no Relatório Robbins de 1963, foram revisadas em uma série de relatórios publicados nas décadas de 1980 e 1990. O University Grants Committee, de 1984, defendeu um enfoque mais abrangente. Enfatizou que 0 ensino de habilidades deveria atender as necessidades da economia e do indivíduo, e que todas as mudanças, fossem elas científicas, tecnológicas ou econômicas, precisavam de um ensino que focalizasse habilidades pessoais e intelectuais transferíveis, valorizadas pela indústria, comércio, profissionais, e administração pública e social. 0 documento 'Higher Education: M eeting the Challenge' confirmou estas metas e acrescentou que os graduados precisavam estar "em sintonia com a cultura empresarial, cientes das necessidades da indústria e do comércio, deveriam saber aprender e ter 
alguma experiência do mundo do trabalho"4 (Bennett et al. 2000, P. 4). 0 Relatório Dearing, de 1997, reafirmou a existência de um contexto econômico em transformação e ressaltou que uma mistura de habilidades era necessária para a sociedade ilustrada do século XXI. D estacou também que a meta e o resultado do ensino superior tinham que ser o desenvolvimento do conhecimento, da compreensão e de habilidades específicas, cognitivas e básicas.

\section{Definindo as habilidades para o trabalho}

A revisão acima sugere uma crescente demanda por habilidades que possam ser aplicadas a uma variedade de campos de trabalho. Aponta também para a confusão que cerca a conceitualização das habilidades para 0 trabalho. Não há nenhuma definição ou acordo universal quanto ao conteúdo de tais habilidades. As habilidades necessárias ao emprego foram discutidas tendo como referência as habilidades que são consideradas como as principais, mais comuns, genéricas, habilidade-chave e transferíveis. Além disso, haveria também os atributos, capacidades e competências.

Ao definir o termo, a maioria das publicações inclui comunicação, habilidades matemáticas, tecnologia de informação e comunicação, habilidades pessoais e interpessoais, e a capacidade de solucionar problemas. A Association of Graduate Recruitersusa o termo 'habilidades de autoconfiança' com o subtítulo 'habilidades de gerenciamento de carreira e habilidades de aprendizagem eficaz', as quais incluem autoconhecimento; autopromoção; saber aproveitar e criar oportunidades; planejamento de ação; saber trabaIhar em rede; habilidades de conciliação, de tomada de decisão, de negociação; ter consciência política; saber lidar com a incerteza; enfocar o desenvolvimento, habilidades de transferir conhecimentos adquiridos para di-

4 Todas as citações foram livremente traduzidas do inglês. 
Sociologias, Porto Alegre, ano 8, no 16, jul/dez 2006, p. 126-155

versas situações; autoconfiança (Hawkins e W inter 1995). O utros incluem atributos pessoais tais como conhecimento, intelecto, vontade de aprender e auto-habilidades, e atributos interpessoais como comunicação, trabalho em equipe e habilidades interpessoais. Em entrevistas e na literatura sobre recrutamento, empregadores destacaram a importância de atributos pessoais - o entusiasmo e a perseverança, por exemplo - no lugar das habilidades (D unne 1999a, b). O Committee of Vice Chancellors and Principals defende uma definição de empregabilidade que inclui "habilidades intelectuais tradicionais, tais como avaliação crítica e a transferência da teoria à prática, as novas habilidades-chave ou básicas, atributos pessoais como flexibilidade e autoconfiança, e conhecimento a respeito do funcionamento das organizações" (N oble 1999, p. 122). Há ainda outros que incluem participar de projetos acadêmicos sem qualquer ligação com o mundo do trabalho, entre as atividades que potencializam a empregabilidade (Harvey 2001). A despeito desta confusão quanto ao conceito de empregabilidade, parece haver um consenso de que as habilidades de empregabilidade incluem competências gerais, pessoais e intelectuais que não são ensinadas abertamente nas disciplinas acadêmicas tradicionais e nas habilidades de aprendizagem (N oble 1999).

Divergências quanto à conceitualização das habilidades de empregabilidade originaram debates sobre o desenvolvimento e a transferência de habilidades. Em meados da década de 90, o Department of Employment ressaltou que as habilidades básicas são todas aquelas que podem ser transferidas a uma variedade de contextos. Todas as habilidades básicas são, conseqüentemente, habilidades transferíveis e podem ser identificadas e transferidas entre a aprendizagem e os contextos de trabaIho (Bennett et al. 2000). Little (2001), no entanto, destaca as muitas dimensões de empregabilidade do graduado. Estas incluem indicadores relacionados à aquisição do emprego (por exemplo, velocidade para empregar- 
se, nível do emprego, remuneração) e aqueles relacionados à preparação para o emprego (por exemplo, a relação entre o curso e o tipo de emprego obtido, opinião do graduado sobre deficiências nas habilidades adquiridas). Para Little, uma avaliação da qualidade e relevância do ensino superior para a empregabilidade do graduado requer uma definição mais clara do conceito de empregabilidade e a compreensão da influência que o ensino superior tem sobre o emprego.

M uitos dos membros da comunidade acadêmica afirmam que as habilidades de empregabilidade têm sido ensinadas de forma implícita em programas de ensino e questionam a necessidade de mudança nas estratégias de ensino e aprendizagem. Entretanto é amplamente aceito o fato de que muitos estudantes podem não estar cientes do desenvolvimento de habilidades e, em última instância, não serem capazes de aplicar seus conhecimentos e habilidades de maneira eficaz nos contextos de trabalho (N oble 1999). Em resposta a essa constatação e também ao ambiente econômico e político em evolução, as universidades começaram a desenvolver estratégias que incorporavam o desenvolvimento de habilidades para a empregabilidade ao conjunto disciplinar acadêmico e à avaliação dos resultados da aprendizagem. Com isso, as universidades puderam recorrer ao apoio do programa Enhancing Student Employability Co-ordination Team (ESECT), definida pelo HigherEducation Funding Council (HEFCE) em 2002, que oferecia um excelente conjunto de recursos desenvolvido pela ESECT, disponível no sítio da Higher Education Academy.

\section{Modelos de desenvolvimento da habilidade de empregabilidade}

0 desenvolvimento de um quadro referencial para o ensino de habilidades de empregabilidade formou-se a partir de três perspectivas teóricas 
Sociologias, Porto Alegre, ano 8, no 16, jul/dez 2006, p. 126-155

básicas: a abordagem de capacidades, o modelo Compreensão, Habilidades, Eficácia, Empregabilidade, M etacognição (U nderstanding, Skills, Efficacy, Employability, Metacognitions) - U SEM,$^{5}$ e a abordagem da aprendizagem situada.

Abordagem de capacidades

D efensores desta abordagem acreditam na capacidade de as pessoas definirem suas próp rias necessidades de desenvolvimento em um determinado contexto e controlar sua própria aprendizagem. Essa abordagem pretende promover a autonomia pessoal na aquisição, desenvolvimento e aplicação do conhecimento, das habilidades, das qualidades pessoais, e da compreensão. Ela propõe que os estudantes participem na formulação de suas própriasnecessidades educacionais, no planejamento de um programa adequado, na utilização de recursos e informações apropriados, na identificação de metas, na avaliação de realizações em relação às metas e na preparação de um plano de desenvolvimento. Em resumo, a abordagem defende uma mudança de 'um modelo de ensinar o conhecimento para outro que permite a aprendizagem' (Stephenson 1998, p. 8). Stephenson aponta uma série de obstáculos em potencial para a implementação de tal modelo. Por exemplo: o modelo exige uma nova maneira de pensar 0 ensino, uma vez que os programas e estratégias são definidos por professores, sem qualquer participação real por parte dos estudantes. Além disso, os diplomas são baseados na acumulação de créditos e não, na coerência e integridade dos programas em termos de necessidades de desenvolvimento dos estudantes.

\section{Modelo USEM}

U ma evolução da abordagem de capacidades foi proposta por Knight e Yorke $(2000,2002)$ que sugerem que a empregabilidade é influenciada

5 M odelo criado por Peter Knight e Mantz Yorke $(2000,2002)$. 
pela compreensão que as pessoas têm (de uma disciplina ou de um campo profissional), pelas habilidades (específicas e genéricas), pela crença na eficácia (confiança na capacidade de fazer a diferença) e pela fluência metacognitiva (a consciência de como agem, aprendem e desenvolvem suas capacidades). 0 modelo afirma que o desenvolvimento do currículo precisa agregar o conceito de capacidade às teorias do self. Para D weck (1999, p. 37), a teoria adotada pelos estudantes 'afeta aquilo que eles valorizam, a forma como abordam tarefas intelectuais, e o modo como interpretam e reagem ao que Ihes acontece'. As pessoas podem não estar cientes dessas teorias, de suas expectativas, receios ou objetivos, mas podem ser inconscientemente afetadas e responderem de acordo. Knight e Yorke $(2002$, p. 18) afirmam que as universidades podem melhorar a empregabilidade dos estudantes, ao enfocarem o desenvolvimento de suas 'metacognições, que é a consciência que cada um tem de suas próprias capacidades'. Para isso, é necessário que a empregabilidade seja inserida nas metas e no projeto do currículo, nas estratégias de aprendizagem e ensino, e que existam avaliações no decorrer do curso de graduação. As estratégias da universidade podem ser complementadas por estágios de trabalho, de curta duração e não-compulsórios, durante os anos de estudo, com o objetivo de preparar estudantes para o mundo do trabalho.

Abordagem da aprendizagem situada

O s proponentes dessa abordagem enfatizam a importância do contexto da aquisição de conhecimentos para a subseqüente aplicação em outras situações ou contextos. Para eles, a questão fundamental é o modo como um contexto prepara as pessoas para outro. Bennett et al. (2000) sugerem cinco áreas de provisão de empregabilidade - conhecimento disciplinar, habilidades disciplinares, habilidades genéricas, consciência do local de trabalho e experiência no local de trabalho - mas são flexíveis quanto ao local e a forma como o conhecimento e as habilidades podem ser pro- 
Sociologias, Porto Alegre, ano 8, no 16, jul/dez 2006, p. 126-155

porcionados. Assim, o conhecimento e as habilidades disciplinares, bem como as habilidades genéricas, podem ser adquiridos em um contexto universitário para uso posterior no local de trabalho ou vice-versa. A experiência de trabalho pode ser obtida com exercícios de simulação do local de trabalho dentro do curso ou através de estágios junto a empregadores. As habilidades podem ser ensinadas como parte de um módulo ou em cursos separados. Algumas disciplinas podem identificar habilidades relacionadase serem ensinadas como habilidades básicas inseridas no contexto do ensino de matérias. $O$ utras disciplinas podem identificar as mesmas habilidades como genéricas e serem ensinadas em cursos independentes. A fim de acomodar a diversidade na compreensão das habilidades, o modelo desenvolveu quatro amplas habilidades de gerência - de si mesmo, do outro, da informação e das tarefas - que são genéricas e podem potencialmente ser aplicadas a qualquer disciplina, curso, local de trabalho, ou contexto. Além disso, esse modelo identifica sub-habilidades, em cada uma dessas quatro áreas, que podem ser acrescidas ou adaptadas para diferentes propósitos de curso e currículo.

\section{Metodologia}

U m questionário estruturado foi desenvolvido e distribuído entre estudantes, no início ou, então, perto do fim de palestras. A finalidade da pesquisa foi explicada, e as instruções para o preenchimento, fornecidas pelo pesquisador, que continuou presente. Esta abordagem contribuiu para evitar o problema da falta de respostas e facilitou o retorno dos questionários. A amostra era composta por 60 estudantes de graduação que cursam bacharelado em políticas sociais e bacharelado combinado em políticas sociais e sociologia. Todos os 60 questionários foram devolvidos, e as questões individuais tiveram uma taxa de respostas entre $80 \%$ e $100 \%$. A análise de duas questões abertas que permitiam ao estudante oferecer informação adicional sobre o desenvolvimento das habilidades em seus programas de 
estudo, foi abandonada porque pouquíssimos estudantes haviam respondido. 0 questionário solicitou aos entrevistados que fizessem escolhas entre listas de afirmações, utilizando a escala Likert de 1-5, ou escolhessem suas preferências a partir de uma lista das respostas oferecidas.

Perspectivas do estudante

Esta seção analisa a visão dos estudantes quanto à provisão e o desenvolvimento das habilidades de empregabilidade em programas de política social. 0 s participantes foram convidados a avaliar a importância da provisão e indicar suas preferências com relação ao que deveria ser reforçado e avaliado nas habilidades de empregabilidade. As subseções abaixo destacam alguns dos resultados mais importantes.

Habilidades de empregabilidade - importância, provisão e expectativas

Ao avaliarem a importância da provisão de habilidades de empregabilidade, os estudantes foram instados a responder sobre três áreas: importância das habilidades de empregabilidade para o emprego, situação atual do ensino dessas habilidades em seus cursos de graduação, e vontade de adquirir habilidades de empregabilidade. Responderam as três indagações propostas 54 estudantes (90\%). As definições de habilidades de empregabilidade variam bastante. Por isso, foi construída uma lista das habilidades apresentada aos estudantes, para que avaliassem sua importância, usando uma escala de cinco pontos. A Tabela 1 apresenta um resumo dos resultados dessas três perguntas.

Importância das habilidades para o emprego

Para assinalar a importância de determinadas habilidades para o emprego, foi utilizada uma escala que variava de 'muito importante' (5) até 'irrelevante' (1). Cinco habilidades foram avaliadas como 'muito importantes' por quase dois terços dos entrevistados e 'importantes' por um quarto: trabalho em equipe $(97 \%)$, autoconfiança $(92 \%)$, definição de metase 
Sociologias, Porto Alegre, ano 8, no 16, jul/dez 2006, p. 126-155

Tabela 1- Índices para habilidades de empregabilidade - importância, provisão,

Expectativas

(número das respostas $=54$ )

\begin{tabular}{llll}
\hline Expectativas & A & B & C \\
\hline capacidade de aplicar as habilidades a novos contextos & 94 & 63 & 83 \\
habilidades analítico-críticas & 83 & 78 & 96 \\
consciência empresarial & 60 & 14 & 63 \\
planejamento de carreira e gerência & 84 & 28 & 78 \\
capacidade de lidar com a incerteza & 61 & 34 & 61 \\
definição de metas \& gerenciamento de tempo & 89 & 69 & 76 \\
tomada de decisão & 87 & 50 & 82 \\
tecnologia de informação & 82 & 46 & 81 \\
agregar informação e pesquisa & 91 & 83 & 93 \\
liderança & 69 & 24 & 48 \\
aprendizagem e desenvolvimento pessoal & 85 & 58 & 79 \\
capacidade de negociação & 50 & 30 & 63 \\
trabalho em rede & 67 & 26 & 63 \\
habilidades matemáticas & 70 & 33 & 59 \\
apresentações orais & 78 & 53 & 70 \\
consciência das relações de poder & 74 & 39 & 67 \\
solução de problemas & 81 & 46 & 81 \\
estruturas de relatório e escrita & 87 & 74 & 92 \\
consciência de si & 85 & 46 & 69 \\
autoconfiança & 92 & 45 & 76 \\
autopromoção & 79 & 30 & 62 \\
trabalho em equipe & 97 & 57 & 94 \\
\hline
\end{tabular}

O bservação:

A coluna $A$ indica a porcentagem de estudantes que avaliaram a habilidade como 'muito importante' e 'importante' para o emprego e carreiras.

A coluna $B$ indica a porcentagem de estudantes que 'concordam totalmente' e 'concordam' que a habilidade está sendo ensinada em seu curso de graduação atualmente.

A coluna $C$ indica a porcentagem de estudantes que foram 'totalmente a favor' e 'a favor' de desenvolverem a habilidade em seu curso de graduação. 
Sociologias, Porto Alegre, ano 8, no 16, jul/dez 2006, p. 126-155

gerenciamento de tempo (89\%), tomada de decisão (87\%), e estrutura de texto e escrita (87\%). 0 utras seis habilidades obtiveram entre $91 \%$ e $82 \%$, embora a gradação estivesse dividida quase que igualmente entre as categorias 'muito importante' e 'importante': agregar informação e pesquisa, habilidades de transferência, aprendizagem e desenvolvimento pessoal, planejamento de carreira e gerência, habilidades analítico-críticas, e tecnologia de informação. 0 s empregadores enfatizam cada vez mais a procura por habilidades cognitivas de alto nível, que permitam ao indivíduo transferir e aplicar aquisiçõesa uma grande variedade de contextos. Pillay (1998, p. 75) define habilidades cognitivas de alto nível como 'raciocínio crítico, solução de problemas e pensamento criativo que (...) ajude a aumentar a compreensão profunda e, conseqüentemente, potencializar a transferibilidade do conhecimento e das habilidades. N essa pesquisa, tais habilidades receberam índices elevados (habilidades de transferência: $89 \%$, habilidades analítico-críticas: $83 \%$ ), mas outras, tais como trabalho em equipe e autoconfiança, foram consideradas mais importantes.

Provisão de habilidade nos cursos de graduação

Para qualificar a provisão de habilidades de empregabilidade em seus cursos de graduação, os estudantes examinavam uma escala que variava de 'concorda totalmente' (5) até 'discorda totalmente' (1). Desta vez, somente duas das cinco habilidades apontadas pela maioria dos estudantes como sendo 'muito importantes' ou 'importantes' para o emprego obtiveram índices elevados. Dentre os entrevistados, $74 \%$ 'concordaram totalmente' ou 'concordaram' que estrutura de texto e escrita estavam sendo ensinadas, e $69 \%$ consideraram que foram ensinadas definição de metas e gerenciamento de tempo. As três habilidades restantes receberam o apoio de aproximadamente metade dos entrevistados: trabalho em equipe, tomada de decisão e autoconfiança. Das habilidades que obtiveram quase a mesma votação como 'muito importantes' e 'importantes' para o emprego, 
Sociologias, Porto Alegre, ano 8, no 16, jul/dez 2006, p. 126-155

duas receberam índices elevados: agregar informação e pesquisa (83\%) e habilidades analítico-críticas (78\%). É importante destacar que o planejamento de carreira e as habilidades de gerência, que, como já era esperado, receberam índices elevados no que diz respeito à relevância para o emprego $(84 \%)$, tiveram pontuações muito baixas no escore de ensino $(28 \%)$.

Predisposição para o desenvolvimento de habilidade

Até que ponto os estudantes gostariam de desenvolver habilidades específicas em seus cursos de graduação? As habilidades identificadas como sendo 'muito importante' e 'importante' para o emprego também apareceram proeminentemente na lista de preferências para o desenvolvimento de habilidades. Em uma escala de 'totalmente a favor' (5) até 'totalmente contra' (1), quase todos os entrevistados responderam que são 'totalmente a favor' ou 'a favor' de desenvolver habilidades analítico-críticas (96\%), trabalho em equipe (94\%), agregar informação e pesquisa (93\%), e estrutura de texto e escrita (92\%). O utras habilidades que obtiveram forte apoio foram as de transferência, tomada de decisão, definição de metas e gerenciamento de tempo, e autoconfiança. Q uase todos os estudantes apoiaram o desenvolvimento do planejamento de carreira e das habilidades de gerência, embora apenas $46 \%$ tenham votado 'totalmente a favor' de desenvolver a habilidade.

Potencializando as habilidades de empregabilidade

As habilidades de empregabilidade podem ser desenvolvidas de diversas formas. M uito se debateu se tais habilidades devem ser desenvolvidas em módulos separados, ou agregadas dentro de módulos temáticos, de matéria. Para se obter a opinião dos estudantes, foram propostas questões a respeito da aquisição de habilidades de empregabilidade e de suas preferências quanto ao desenvolvimento de tais habilidades. 
Sociologias, Porto Alegre, ano 8, no 16, jul/dez 2006, p. 126-155

Aquisição de habilidades

O s estudantes foram convidados a especificar como haviam adquirido habilidades de empregabilidade até então. Todos os 60 estudantes responderam à questão. 0 s resultados, no entanto, não mostraram predominância de uma determinada fonte. 0 emprego de meio expediente, 0 estudo independente e a participação em algum módulo de habilidades foram mencionados por aproximadamente um terço da amostra. Além disso, a maioria de estudantes (62\%) apontou mais de uma fonte. As combinações variam bastante. A dificuldade para se estabelecer o papel das universidades no desenvolvimento da empregabilidade dos estudantes foi abordada por outro estudo, que concluiu que uma das razões é que muitos estudantes, incluindo alunos em turno integral, estão ao mesmo tempo empregados (H arvey 2001; Little 2001).

Preferências para o desenvolvimento de habilidades

O sestudantes foram convidados a responder dois exercícios para definir suas preferências quanto à potencialização das habilidades de empregabilidade. No primeiro, era fornecida uma lista de estratégias institucionais e iniciativas direcionadas que foram ad otadas por universidadese eles precisavam marcar uma opção em cada lista (ver Tabela 2). Entre o total de entrevistados, 48 e 58 estudantes, respectivamente, completaram o exercício. Em ambos os casos, os resultados mostraram uma preferência declarada. Como estratégia institucional, mais da metade dos estudantes (53\%) escolheu um padrão, que misturava diversas estratégias universitárias (cross-university), que definia as expectativas e os resultados para cada ano acadêmico, padrão esse que pode ser adaptado para servir aos diversos contextos departamentais ou de disciplina. Como iniciativa direcionada, a maioria (40\%) optou por um esquema de aprendizado com base no trabalho. 0 esquema envolve estágios e oficinas de desenvolvimento de habilidades por toda a universidade e requer acordos de apren- 
Sociologias, Porto Alegre, ano 8, no 16, jul/dez 2006, p. 126-155

dizagem firmados entre aluno, tutor e empregador. 0 utra opção bastante aceita, com o apoio de $28 \%$ dos entrevistados, foi a das atividades de aprendizagem baseadas em estudo de caso, que associam o conteúdo acadêmico a situações do mundo real, para desenvolver habilidades específicas.

U m segundo exercício a respeito das estratégias preferidas para a potencialização das habilidades proporcionou aos estudantes a oportunidade de escolherem opções menos específicas. Todos os 60 participantes responderam ao exercício. 0 baixo índice de respostas do primeiro exercício pode ser devido à dificuldade dos estudantes em escolher entre estratégias sobre as quais não tenham experiência em sua própria universidade. Entretanto os resultados confirmam aquele do primeiro exercício. 0 s estudantes preferem que o ensino de habilidades esteja integrado ao ensino da matéria ou que esta seja oferecida à provisão das habilidades, combinada com um módulo baseado em estágios de trabalho. No que diz respeito ao momento e à duração da provisão de habilidades ( 56 respostas), ficou clara a preferência dos estudantes pelo ensino das habilidades durante todo 0 curso de graduação.

Avaliando as habilidades de empregabilidade

Q uestões sobre a avaliação podem dar uma idéia do comprometimento dos estudantes com o desenvolvimento das habilidades de empregabilidade. Para conhecer a opinião dos mesmos sobre o assunto, foram apresentadas diversas afirmações sobre o grau de importância que deve ser atribuído às habilidades de empregabilidade em relação às habilidades disciplinares, e possibilidades quanto ao tipo e à forma de avaliação.

A primeira pergunta recebeu 59 respostas. M etade dos participantes respondeu que as habilidades de conhecimento disciplinar e de empregabilidade devem ter a mesma importância nos programas de ensino. U m terço preferiu que as habilidades fossem usadas para potencializar o estudo das matérias, mas as considerou menos importantes do que 0 conhecimento disciplinar. 
Sociologias, Porto Alegre, ano 8, no 16, jul/dez 2006, p. 126-155

No total, os resultados mostraram uma preferência declarada para a não avaliação das habilidades de empregabilidade (63\% de 58 retornos). Em resposta a uma questão sobre como avaliar as habilidades (56 respostas), aproximadamente a metade da amostra optou por provas escritas, mas nenhuma atribuição de nota (47\%). Q uanto à forma de avaliação (56 respostas), a maioria de estudantes votou por uma combinação. Não havia nenhuma preferência absoluta, mas a maioria das escolhas continha apresentações orais ou então um portfólio composto por uma variedade de atividades e tarefas do curso. Como avaliação única, o portfólio foi votado por um quinto a mais da amostra, o que indica que esta forma de avaliação seria apoiada por mais do que um terço dos entrevistados.

$\mathrm{Na}$ última pergunta sobre a avaliação, os estudantes foram questionados sobre quem seriam seus avaliadores preferidos para as habilidades de empregabilidade. A maioria dos 57 entrevistados (30\%) selecionou o tutor e um avaliador externo, como, por exemplo, um empregador. M enos do que um quarto da amostra preferiu que o tutor fosse o único avaliador. Nenhum dos estudantes escolheu seus colegas, e apenas um optou pela auto-avaliação.

\section{Concluindo a discussão}

Nos contextos em evolução, que são o mercado e os ambientes de trabalho, o ensino superior vem sofrendo crescente pressão para desenvolver a empregabilidade dos estudantes e tornar-se mais relevante no que diz respeito às necessidades dos empregadores. 0 governo se vem preocupando cada vez mais com as necessidades da economia em transformação. No caso das universidades, essa preocupação incentivou a reforma do currículo. Em níveis variados de aceitação e resistência, o tradicional currículo com enfoque na disciplina está cedendo lugar a uma educação que oferece embasamento acadêmico com habilidades de empregabilidade. Decisões 
Sociologias, Porto Alegre, ano 8, no 16, jul/dez 2006, p. 126-155

sobre a inserção de habilidades de empregabilidade no currículo dependem de fatores institucionais e disciplinares. Não obstante, para que uma estratégia seja bem sucedida, ela depende também da participação dos estudantes. Ao examinar as atitudes dos estudantes em três áreas-chave provisão, potencialização e avaliação - este artigo isolou algumas de suas preferências para o desenvolvimento do ensino das habilidades de empregabilidade. Entretanto deve-se ressaltar, mais uma vez que, uma pesquisa das opiniões de uma pequena amostra não pode ser representativa das opiniões da vasta população estudantil. Além disso, o uso de um questionário objetivo não explora em profundidade a opinião dos entrevistados (Denscombe 2002). A validade das respostas foi maximizada através da coleta de dados sobre alguns dos tópicos em mais de uma pergunta ou exercício, e também pela presença do pesquisador durante a aplicação dos questionários para dirimir quaisquer dúvidas. A seção a seguir aponta algumas implicações para que um projeto de curso de graduação concilie as opiniões de estudantes com as exigências de resultado do aprendizado.

Como mencionado anteriormente, há uma disputa visível na literatura quanto ao que constitui as habilidades de empregabilidade. Knight e Yorke (2002) sustentam que a força de uma definição ampla é que esta pode ser aplicada a muitas situações de aprendizagem e não apenas àquela que está relacionada ao mundo do trabalho. Para este artigo, optou-se por uma definição ampla, e os estudantes receberam uma lista das habilidades que foram incluídas no termo. A maioria dos entrevistad os identificou habilidades de aprendizagem e de transferência como sendo mais importantes para o emprego do que habilidades relacionadas mais especificamente ao trabalho. 0 s respondentes também atribuíram índices elevados às habilidades de aprendizagem e transferência quando questionados sobre quais as habilidades que prefeririam desenvolver. Pode ser preocupante o fato de que a maioria dessas habilidades não teve índices elevados na provisão de ensino. 0 s resultados levantam questões relevantes para o desenvolvimen- 
to da aprendizagem, habilidades genéricas ou de transferência, ao lado do ensino do conhecimento disciplinar para reforçar a empregabilidade do estudante. 0 que é bastante importante, uma vez que a pesquisa descobriu que um número elevado de graduados é admitido em empregos não relacionados ao seu curso de graduação (Shah et al. 2004). Apesar da oposição de muitos acadêmicos à promoção do desenvolvimento de habilidades genéricas, muitas instituições estão comprometidas com o ensino de habilidades em suas declarações de missão, diretrizes e procedimentos (M orley 2001). A instituição e a Faculdade cujos estudantes foram entrevistados oferecem cursos de habilidades, identificando elas mesmas as habilidadesa serem desenvolvidas. Com base nos resultados obtidos, parece que a aquisição de tais habilidades não foi feita com sucesso, ou os alunos não tiveram a consciência de sua aquisição. Fica claro também, que os estudantes têm um interesse intrínseco em desenvolver as habilidades. Portanto, parece haver necessidade de: 'formas mais criativas de comunicar, desenvolver e medir habilidades em uma base corrente. U m exemplo poderia ser relacionar o processo de projeto do curso à questão da transferência de aprendizagem (...), isto é, à extensão a qual os processos/tarefas no domínio do aprendizado correspondem àqueles no contexto onde este deve ser aplicado' (Burke et al. 2005, p. 141).

De que forma o currículo pode ser reformado para reforçar as habilidades de empregabilidade dos estudantes? Muito se debateu, sem que houvesse qualquer acordo sobre métodos de ensino e estilos de aprendizagem pelos quais as pessoas melhor adquirem, desenvolvem e transferem conhecimento, compreensão, competência e habilidades para atuar de maneira eficaz dentro e fora da universidade (Cryer 1998; Atkins 1999; Foley 1999; Morley 2001). Para o desenvolvimento de habilidades de empregabilidade, as instituições adotaram diferentes abordagens. Em termos gerais, estas podem ser classificadas como estratégias institucionais e/ ou iniciativas direcionadas. 0 ensino de habilidades de empregabilidade 
Sociologias, Porto Alegre, ano 8, no 16, jul/dez 2006, p. 126-155

tem sido oferecido em cursos independentes, dentro e fora das faculdades, e/ou foi agregado a módulos de matérias, seja com tarefas de aprendizagem em locais de trabalho, seja através de estágios de trabalho e experiência. De fato, Noble (1999, p.132) sustenta que o desenvolvimento de habilidades de empregabilidade não pode ser obtido com uma única abordagem. Ela sugere que uma estratégia bem sucedida, além do fator-chave que é a 'aprendizagem ativa', exige que a provisão seja programada, creditada, relevante, realista, integrada, avaliada, graduada, apoiada, direcionada ao objetivo e flexível.'

De acordo com D arvill (2004, p. 14), 'em algumas disciplinas há evidência de que a realização de atividades no ambiente de trabalho, supervisionadas por profissionais, reforça a aprendizagem dos conceitos, teorias, princípios e temas amplos do ensino acadêmico, ao proporcionar ao estudante a chance de testá-los. Este aprendizado estabelece a criação de novas teorias, embasadas ou tácitas, do próprio estudante, e um retorno revigorado à matéria ensinada.' Coincidentemente, uma ligação com o 'local de trabalho' está de acordo com as preferências dos estudantes. 0 s participantes deste estudo preferiram um modelo integrado de desenvolvimento das habilidades de empregabilidade. A maioria dos participantes é favorável à aprendizagem com base no trabalho, através de estágios combinados com oficinas dentro da universidade. U ma segunda preferência foi a dos estudos de caso que agregam o conteúdo acadêmico com situações de trabaIho imaginadas. A maior parte dos estudantes defendeu a existência de uma estratégia institucional para o desenvolvimento das habilidades de empregabilidade. A instituição definiria as expectativas e resultados esperados no desenvolvimento de habilidades ao longo do curso de graduação. U ma flexibilidade natural seria a garantia de que o desenvolvimento das habilidades poderia ser adaptado aos contextos departamentais ou de disciplina.

Esses resultados acarretam implicações para a provisão do ensino. À época da pesquisa, o desenvolvimento de habilidades na instituição partici- 
pante era oferecido em sessões no Centro de Desenvolvimento e Aprendizagem (Learning and Development Centre) e no Serviço de Carreiras (Careers Services), por toda a extensão do curso e, em uma unidade de habilidades, dentro da faculdade, direcionada aos estudantes do primeiro ano. À exceção da provisão oferecida pelo Serviço de Carreiras, nenhuma das outras provisões da instituição enfocava especificamente o desenvolvimento de habilidades de empregabilidade. U ma estratégia institucional e um modelo integrado de desenvolvimento exigiriam mudanças no que diz respeito à política da universidade, à estrutura do currículo e ao conteúdo dos módulos individuais de matéria. Poderiam também requerer a persuasão de alguns acadêmicos que podem temer um currículo sobrecarregado ou submetido ao ensino de habilidades (N oble 1999). Essa mudança afetaria também a equipe de funcionários e os recursos físicos. Os professores do curso acadêmico precisariam desenvolver sua compreensão dos diversos aspectos da empregabilidade e sua capacidade para agregar componentes das habilidades no currículo acadêmico e nas atribuições. Além disso, a precária situação financeira da universidade e a redução de pessoal contribuem para o aumento da carga horária dos professores e para a diversificação das áreas sob a responsabilidade de professores individuais. 0 tempo para desenvolver novas e instigantes estratégias de ensino será reduzido. Conseqüentemente, há uma série de fatores que trabalham para inibir a reforma. Entretanto, conforme sugere Atkins (1999, p. 277), "instituições individuais podem tentar obter vantagem no mercado de estudantes, ou podem ser levadas a fazê-lo se estiverem experimentando uma grave redução no número de estudantes e atribuírem o fato à falta de empregabilidade de seus graduados".

As habilidades de empregabilidade devem ser avaliadas? Como? Os últimos anos viram a promoção e o movimento gradual em direção à avaliação baseada em critérios. É uma abordagem formal, que requer o desenvolvimento de objetivos, resultados de aprendizado, critérios pré-especifica- 
Sociologias, Porto Alegre, ano 8, no 16, jul/dez 2006, p. 126-155

dos de avaliação e padrões. As atribuições são então avaliadas de acordo com exigências definidas (Gibbs et al. 1988; Paczuska 1994). 0 sistema foi elogiado pela sua justiça, uma vez que os estudantes estão conscientes do que se espera deles, e também porque relaciona a avaliação aos resultados de aprendizado, que podem ser publicamente justificados perante todos os interessados (Knight 1995). Todavia o sistema foi criticado por ser complexo (Pazcuska 1994), artificial (Knight 1995) e inflexível (Gibbs 1998). Alguns autores mencionaram a dificuldade de usar a avaliação baseada em critérios para o aprendizado de habilidade, uma vez que será difícil medir o sucesso nesta área (Garrett 1999; N oble 1999; Yorke 2001; W right 2001). Ao mesmo tempo em que a necessidade de algum tipo de crédito e avaliação é considerada imprescindível para que o desenvolvimento das habilidades seja levado a sério pelos estudantes, a literatura, na maioria das vezes, apóia abordagens de avaliação informais e flexíveis que incentivam os estudantes a refletirem e registrarem o seu desenvolvimento na área. Esta abordagem está de acordo com o Code of Practice for Placement Learning of the Q uality Assurance Agency for Higher Education (Q AA), o qual estipula que os estudantes devem assumir a responsabilidade pelo planejamento do desenvolvimento pessoal e registrar seus progressos e realizações (Fell et al. 2004).

Tal abordagem está de acordo com as preferências dos entrevistados. A maioria dos participantes foi contra uma avaliação formal por conceitos. Há indicações claras de que um conjunto de evidências (um portfólio, por exemplo) e uma consideração sobre o material são a forma de avaliação preferida para este tipo de aprendizado. 0 s resultados mostram também que qualquer avaliação de evidência deve estar na forma de retorno escrito pelo tutor, sem notas concedidas. Esse resultado levanta uma série de questões. Para que a conceituação seja eficaz, as observações precisam destacar os pontos fortes e os fracos. 0 s professores não foram treinados para ensinar habilidades nem para ensinar no trabalho, sendo improvável que tenham competência e habilidade para avaliar o desenvolvimento das habilidades de empregabilidade dos estudantes. Eles precisarão levar em consi- 
deração a competência dos membros da equipe do Centro de Desenvolvimento e Aprendizagem e possivelmente a dos empregadores para preparar os critérios da avaliação e as observações na conceituação. Esse desenvolvimento tem claras implicações em termos de pessoal para o Centro de Desenvolvimento e Aprendizagem. Ao considerar dois avaliadores adicionais, um dos quais de base não-universitária, o desenvolvimento e a gerência da matéria agregada e dos módulos de habilidades poderiam realmente consumir muito tempo. Exigiriam um alto nível de coordenação, negociação e comprometimento. Além disso, o uso de empregadores como avaliadores é controverso, principalmente porque, em muitos casos, eles não se terão submetido a qualquer forma de treinamento em avaliação. Longo prazo, a adoção de módulos integrados matéria-habilidade se beneficiaria com professores de curso acadêmicos que estão sendo treinados em um novo conjunto de habilidades voltadas para o apoio ao aluno.

É interessante mencionar que as abordagens da auto-avaliação e da avaliação pelos colegas foram rejeitadas pelos entrevistados. Por algum tempo, a literatura educacional incentivou os acadêmicos a introduzirem a autoavaliação. Entre as razões alegadas, argumentava-se que estes métodos criam um ambiente de aprendizagem que leva ao engrandecimento e a autodeterminação. Esperava-se que incentivassem os estudantes a desenvolverem habilidades transferíveis e de avaliação, tornando-se estudantes autônomos, com o papel de parceiros ativos no processo de aprendizagem. No entanto, a rejeição quase que unânime da oportunidade de participar na avaliação coloca em dúvida o nível de envolvimento que os estudantes buscam na realização dos programas de desenvolvimento de habilidades, assim como no desenvolvimento do currículo e das metodologias de ensino.

Até que ponto os resultados finais sustentam os modelos teóricos? 0 questionário de pesquisa demonstra que os estudantes são a favor da aprendizagem baseada no trabalho e da consciência sobre o trabalho que adquirem em um ambiente simulado para desenvolver as habilidades de empregabilidade. 0 s resultados inserem-se no modelo de aprendizagem 
Sociologias, Porto Alegre, ano 8, no 16, jul/dez 2006, p. 126-155

situada no trabalho desenvolvido por Bennett et al. (2000). De acordo com esse modelo, a chave para uma maior empregabilidade é a maneira como um ambiente prepara as pessoas para outro ambiente. 0 modelo afirma que a empregabilidade do indivíduo pode ser potencializada por uma educação que ofereça conhecimento disciplinar, habilidades disciplinares, habilidades genéricas, consciência do ambiente de trabalho e experiência no mesmo. Como estes diferentes elementos devem ser oferecidos, depende do contexto local. 0 modelo admite uma flexibilidade considerável e, desta forma, pode acomodar interesses diversos no projeto de uma estrutura de currículo que pretenda atender às diferentes finalidades e intenções do curso .

Em geral, os estudantes de ciência sociais não buscam um emprego específico (Harvey 2001). No entanto muitos trabalham no campo do bemestar social e em serviços públicos. Podem precisar pesquisar e escrever relatórios e artigos sobre políticas. Podem aconselhar clientes a respeito de seus benefícios e direitos. Holmes (2001, p. 117-18) alega que os cursos com alguma orientação vocacional (política social, por exemplo) podem desenvolver habilidades relacionadas ao trabalho, pela introdução no programa de ensino de tarefas com relevância para algumas das exigências e práticas dos campos ocupacionais tipicamente escolhidos pelos estudantes da disciplina. M esmo os cursos sem qualquer orientação vocacional (Sociologia, por exemplo) podem desenvolver habilidades relacionadas ao trabaIho, através do desenvolvimento de tarefas para práticas imaginativas em uma série de campos e/ou níveis ocupacionais de emprego tipicamente procurados por graduados, em oposição aos não-graduados. 0 modelo de aprendizagem situada parece ser suficientemente flexível para permitir aos estudantes que adquiram o conhecimento disciplinar e as habilidades de aprendizagem necessárias ao desenvolvimento e à realização educacionais, bem como as habilidades de aprendizagem do ambiente de trabalho necessárias para melhorar sua empregabilidade. 
Tabela 2 - U ma lista de estratégias e iniciativas desenvolvidas por universidades para reforçar as habilidades de empregabilidade dos estudantes

Estratégias Institucionais

1. Padrões universitários definindo expectativas de habilidade e resultados para cada ano acadêmico. Podem ser adaptados para servir aos diferentes contextos departamentais (da disciplina). Elementos específicos de habilidade são agregados aos módulos individuais.

2. U m padrão universitário definindo expectativas e resultados da habilidade somente para cadeiras do primeiro ano. Podem ser adaptados para servir aos diferentes contextos departamentais (da disciplina). Elementos específicos da habilidade são agregados nos módulos individuais.

3. U m padrão universitário para um módulo de independente de habilidades que possa ser adaptado para servir aos diferentes contextos departamentais (da disciplina).

4. U ma das opções listadas nos itens 1-3, mas os padrões são desenvolvidos pela Faculdade.

Iniciativas direcionadas

1. Atividades de aprendizagem baseadas em estudo de caso: o conteúdo acadêmico é associado com situações do mundo real para desenvolver habilidades específicas.

2. Uso da tecnologia de informação e de comunicação para proporcionar apoio material às habilidades, incluindo instruções, orientação, exercícios independentes e interativos, e auto-avaliação.

3. U m programa de oficinas para desenvolver a capacidade de planejamento de carreira dos estudantes, oferecido como um módulo e incluído no curso de graduação.

4. Esquemas de aprendizagem independente realizados pelo estudante: representantes do curso e outros estudantes voluntários recebem treinamento no desenvolvimento de habilidades e facilitação e, então, contribuem para a provisão do curso de habilidades.

5. Esquemas de aprendizagem autogerenciados pelo estudante: estudantes voluntários recebem treinamento no desenvolvimento de habilidades e promovem grupos de auto-ajuda.

6. Esquema de aprendizagem com base no trabalho, envolvendo uma colocação de trabalho e desenvolvimento de habilidades em oficinas, por toda a universidade durante um semestre. Acordos de aprendizagem são assinados entre graduado, tutor e empregadores. 
Sociologias, Porto Alegre, ano 8, no 16, jul/dez 2006, p. 126-155

\section{Referências}

ATKINS, M. J. 'O ven-ready and Self-basting: taking stock of employability skills', Teaching in Higher Education 4 (2), 267-280. 1999.

BEN N ETT, N.; DU N NE, E. e CARRÉ, C. Skills Development in Higher Education and Employment. Buckingham: The Society for Research into Higher Education and $O$ pen U niversity Press. 2000.

BU RKE, V.; JO NES, I. e D O HERTY, M. 'Analysing student perceptions of transferable skills via undergraduate degree programmes', Active Learning in Higher Education 6 (2), 132-144. 2005.

CRYER, P. 'Transferable Skills, Marketability and Lifelong Learning: the particular case of postgraduate research students', Studies in Higher Education 23 (2), 207216. 1998.

DENSCOMBE, M. The Good Research Guide for small-scale social research projects. Buckingham: O pen U niversity Press. 2002.

DARVILL, G. 'Employability and Recruitment', Social Policy Association News, June, 12-15. 2004.

DUNNE, E. 'Change in higher education: a learning society and the role of core skills'. In: DUNNE, E. (ed.), The Learning Society. London: Kogan Page. 1999a.

DUNNE, E. 'Drawing together the threads'. In DUNNE, E. (ed.), The Learning Society. London: Kogan Page. 1999b.

DWECK, C. S. Self-Theories. Hove: Psychology Press. 1999.

FALLO W S, S. and STEVEN, C. 'The skills agenda'. In: FALLO W S, S. and STEVEN, C. (eds.), Integrating key skills in higher education. London: Kogan Page. 2000.

FELL, A. and KUIT, J. A. 'Placement learning and the Code of Practice. Rhetoric or reality?' 4 (3), 214-225. 2003.

FO LEY, P. 'Transferable Skills Teaching: contextual pressures and personal dilemmas'. Teaching in Higher Education 4 (1), 5-25. 1999.

GARRET, H. 'Key Aspects of Teaching and Learning in Social Sciences and Law', In: FRY, H., KETTERIDGE, S. and M ARSH ALL, S. (eds.), H andbook for Teaching and Learning in Higher Education. London: Kogan Page. 1999. 
GIBBS, G.; HABESHAW, S. and HABESHAW, T. Interesting ways to assess your students. Bristol: Technical and Educational Services. 1988.

GIBBS, G. Teaching in Higher Education: theory and evidence. Chapter 4 M arking and Giving Feedback. Milton Keynes: The O pen University. 1998.

HARVEY, L. 'D efining and M easuring Employability', Q uality in Higher Education 7, 2: 97-109. 2001.

HAW KINS, P. and W INTER, J. Skills for Graduates in the 21 ${ }^{\text {st }}$ Century. Cambrdige: The Association of Graduate Recruiters. 1995.

HOLMES, L. 'Reconsidering Graduate Employability: the 'graduate identity' approach', Quality in Higher Education 7 (2), 111-119. 2001.

KNIGHT, P. Assessment for Learning in Higher Education. London: Kogan Page. 1995.

KNIGHT, P. T. and YO RKE, M. Employability through the curriculum. Project 'Skills plus: Employability in Higher Education', Department of Educational Research, Lancaster University, and Centre for Higher Education Development, Liverpool John Moores University. 2000.

KNIGHT, P. and YORKE, M. 'D efining and addressing employability: a fresh approach', Exchange 2 (summer), 15-18. 2002.

LITTLE, B. 'Reading Between the Lines of Graduate Employment', Q uality in Higher Education 7 (2), 121-129. 2001

MILLER, Smith, C. 'A business view of the graduate today', Exchange 2 (summer), 811. 2002.

MO RLEY, L. 'Producing N ew Workers: quality, equality and employability in higher education', Q uality in Higher Education 7 (2), 131-138. 2001.

NO BLE, M. 'Teaching and Learning for Employability', In: FRY, H.; KETTERIDGE, S.; MARSHALL, S. (eds.). Handbook for Teaching and Learning in Higher Education. London: Kogan Page. 1999.

PACZUSKA, A. Learning outcomes - a handbook for course directors. South Bank University. 1994. 
Sociologias, Porto Alegre, ano 8, no 16, jul/dez 2006, p. 126-155

PILLAY, H. 'Cognitive Skills Required in Contemporary Workplaces', Studies in Continuing Education 20 (1), 71-8. 1998.

SHAH, A.; PELL, K. and BRO O KE, P. 'Beyond first destinations', Active Learning in Higher Education 5 (1), 9-26. 2004.

STEPHENSON, J. 'The Concept of Capability and Its Importance in Higher Education'. In STEPHENSO N, J. and YORKE, M. (eds.) Capability and Q uality in Higher Education. London: Kogan Page. 1998.

YO RKE, M . Assessment: A Guide for Senior Managers. York: LTSN Generic Centre. 2001.

WRIGHT, W. A. 'The Dalhousie Career Portfolio Programme: a multi-faceted approach to transition to work', Q uality in Higher Education 7 (2). 149-159. 2001. 


\section{Resumo}

Este artigo examina a postura dos estudantes em relação ao desenvolvimento das habilidades de empregabilidade no ensino superior. A análise se baseia em um questionário de pesquisa apresentado a 60 alunos de graduação, os quais cursaram bacharelado em políticas sociais e bacharelado combinado em políticas sociais e sociologia em uma universidade londrina, criada depois de 1992. A pesquisa examina a opinião que os estudantes têm sobre as habilidades desenvolvidas e sobre suas preferências no que diz respeito ao desenvolvimento das habilidades para a empregabilidade. Os resultados mostram que a maioria dos estudantes considera de igual importância o conhecimento sobre matérias variadas e o desenvolvimento de habilidades relacionadas à empregabilidade. Há total apoio para uma estratégia institucional e um modelo integrado que reforcem as habilidades para a empregabilidade. O s resultados finais endossam a necessidade do desenvolvimento de habilidades para a empregabilidade, no contexto da aprendizagem.

Palavras-chave: desenvolvimento do currículo, habilidades para a empregabilidade, programas de política social, percepção de estudantes.

Recebido: 01/06/06

Aceite final: $21 / 08 / 06$ 


\section{Higher teaching and skill development for employability: exploring the students' view}

\section{M onika Zalauf}

This article explores student attitudes towards employability skills development in higher education. The analysis draws on a questionnaire survey undertaken with 60 undergraduates studying for a single honours social policy degree and a combined honours social policy/sociology degree in one post-1992 University in London. The survey investigates students' perceptions of skills provision, and their preferences for the development and the assessment of employability skills. The findings show that the majority of students consider the development of subject knowledge and employability skills of equal importance. There is clear support for an institutional strategy and an integrated model for the enhancement of employability skills. The overall results support the development of employability skills within the situated learning approach.

Key words: Curriculum development, employability skills, social policy programmes, student perceptions 